\title{
Passion Berwirausaha pada Pengusaha Muda
}

\author{
Petra Merieska ${ }^{1} \mathcal{E}$ IJK Sito Meiyanto ${ }^{2}$ \\ Fakultas Psikologi Universitas Gadjah Mada
}

\begin{abstract}
This study aims to understand understanding the dynamics of passion in youth entrepreneurs when running a business. By understanding the dynamics of passion in running a business, youth entrepreneurs can understand the importance of passion's role to his business so as to avoid failure. In order to achieve these objectives, a phenomenological study was conducted on purposively selected participants, ie nascent or new bussiness entrepreneurs who have passion in entrepreneurship aged 18 to 34 years. Data were collected using semi-structured phenomenological interviews, and analyzed using a phenomenological analysis approach. The results show that the dynamics of passion play an important role in the three series of areas of entrepreneurial activity: 1) product creation and development, 2) business establishment, 3) business development. While also found the aspects of personal, environmental and behaviour that affect the emergence of entrepreneurial passion on them.
\end{abstract}

Keywords: passion; phenomenology; youth entrepreneurs

Abstrak. Penelitian ini bertujuan untuk memahami dinamika passion pada pengusaha muda dalam menjalankan usaha. Dengan memahami dinamika passion dalam menjalankan usaha, pengusaha muda dapat memahami pentingnya peran passion terhadap usahanya sehingga dapat terhindar dari kegagalan. Dalam rangka mencapai tujuan tersebut, maka, sebuah penelitian fenomenologis dilakukan terhadap responden yang dipilih secara purposif, yakni nascent atau new bussiness entrepreneur yang memiliki passion dalam berwirausaha berusia 18 hingga 34 tahun. Data dikumpulkan menggunakan wawancara fenomenologis semiterstuktur, dan dianalisis menggunakan pendekatan analisis fenomenologi. Hasil penelitian menunjukkan bahwa dinamika passion berperan penting pada ketiga rangkaian wilayah aktivitas kewirausahaan, yaitu 1) penciptaan dan pengembangan produk, 2) pendirian usaha, 3) pengembangan usaha. Adapun ditemukan pula aspek personal, lingkungan dan perilaku responden yang memengaruhi kemunculan passion berwirausaha pada dirinya.

Kata kunci : fenomenologi; passion; pengusaha muda;

Pengusaha memiliki peran vital dan mampu menjadi solusi bagi masalah pembangunan ekonomi di suatu negara (Darwanto, 2012). Semakin banyak suatu negara memiliki pengusaha, maka pertumbuhan ekonomi negara tersebut

\footnotetext{
${ }^{1}$ Korespondensi mengenai isi artikel ini dapat dilakukan melalui petra.merieska@mail.ugm.ac.id

2 Atau melalui smeiyanto@ugm.ac.id
}

akan semakin tinggi (Darwanto, 2012). Pengusaha menurut Deniz, Boz dan Ertosun (2011) merupakan seseorang memulai langkahnya dalam melakukan usaha dengan membuat organisasi baru yang diidentifikasi dari adanya peluang atau merevitalisasi organisasi yang sudah berkembang. 
Van Praag dan Versloot (2007) menyebutkan beberapa hal terkait pentingnya kegiatan berwirausaha yang dilakukan oleh pengusaha seperti menciptakan lapangan kerja, kemajuan ekonomi dan sosial negara serta inovasi.

Kew, Herrington, Litovsky dan Gale (2013) menyebutkan sebanyak 73 juta orang muda diperkirakan menjadi pengangguran dan studi yang dilakukan oleh International Labour Organization (ILO) menunjukkan bahwa kaum muda tiga kali lebih mungkin menjadi pengangguran dibandingkan orang dewasa. Maka, sebaiknya ada pilihan alternatif seperti di bidang kewirausahaan yang memungkinkan generasi muda tetap dapat bekerja dan mempromosikan penciptaan lapangan kerja.

Darwanto (2012) selanjutnya menyampaikan untuk dapat meningkatkan pertumbuhan ekonomi dan terciptanya lapangan kerja, setidaknya dibutuhkan pengusaha sekitar $2 \%$ dari total penduduk Indonesia. Liliyah (2015) menyebutkan fakta bahwa jumlah keberadaan pengusaha di Indonesia saat ini hanya sebanyak $0,43 \%$ dari jumlah populasi.

Global Entrepreneurship Monitor yang selanjutnya disebut dengan GEM menyampaikan bahwa dari hasil penelitian yang dilakukan terdapat beberapa indikator untuk mengukur kegiatan kewirausahaan di Indonesia. Indikator tersebut yaitu keterlibatan dalam pendirian usaha baru dan masih pada titik awal (nascent entrepreneurship), kewirausahaan baru (new business ownership), dan kewirausahaan yang sudah mapan (established entrepreuneurship).

Nascent Entrepreneurship Rate mengukur persentase dari populasi berusia 18 - 64 tahun yang telah memulai suatu usaha baru namun masih sangat dini (<3 bulan). New Business Ownership
Rate mengukur persentase dari populasi yang berusia 18 - 64 tahun yang sudah menjalani usaha selama lebih dari tiga bulan tetapi kurang dari tiga setengah tahun. Established Entrepreneurship Rate mengukur persentase dari populasi berusia antara 18 - 64 tahun yang saat ini telah memiliki dan mengelola usaha yang sedang berjalan dan telah membayar upah, gaji, atau pembayaran lainnya kepada pemilik lebih dari 42 bulan.

Aktivitas pengusaha di Indonesia memiliki tingkat yang relatif tinggi pada Total Early-stage Entrepreneurial Activity yang selanjutnya disebut TEA (GEM, 2013). Pengusaha yang termasuk dalam TEA adalah kelompok nascent entrepreneurship dan new business ownership. Keduanya adalah kelompok usaha yang tergolong berada pada tahap awal. Tingkat persentase TEA di Indonesia sendiri mencapai $25,5 \%$.

Kew et al. (2013) dalam laporan Youth Business International and Global Entrepreneurship Monitor selanjutnya menyebutkan $80 \%$ kaum muda di Asia Pasifik dan Asia Selatan merupakan pengusaha TEA yang berbisnis dengan opportunity driven. Kaum muda ini mengacu pada orang-orang yang berusia antara 18 - 34 tahun (Kew et al., 2013).

Beberapa penelitian mengenai kewirausahaan telah berbagi sudut pandang mengenai pencapaian dan tantangan dari pengusaha, praktek hingga saran untuk menjadi sukses (Katz \& Green, 2007). Namun, terdapat isu lain yang berkaitan dengan kewirausahaan yaitu munculnya sosok pengusaha yang mendirikan usaha dengan passion. Passion merupakan fenomena yang paling diamati dari proses kewirausahaan (Smilor, 1997; Baum \& Locke, 2004). Collewaert, Anseel, Crommelink, Beuckelaer \& Vermeire (2016) mengemukakan passion merupakan 
bahan utama untuk kesuksesan dalam berwirausaha.

Cardon, Wincent, Singh dan Dnorvsek (2009) dalam penelitiannya juga telah berusaha untuk memahami bagaimana passion dalam berwirausaha benar-benar bekerja. Pengusaha yang memiliki passion adalah pengusaha yang merasa senang terhadap identitas mereka sebagai pendiri usaha dan menganggap bahwa menjadi pendiri merupakan bagian penting dari diri mereka. Penelitian Cardon, Gregoire, Stevens dan Patel (2013) juga menunjukkan bahwa passion dalam berwirausaha benar-benar meningkatkan kreativitas dan ketekunan pengusaha.

Beberapa peneliti mengatakan bahwa passion merupakan komponen inti dari proses kewirausahaan (Cardon et al., 2013; Cardon et al., 2009; Chen, Yao \& Kotha, 2009; Smilor, 1997). Passion membentuk keinginan untuk bertindak dan berperilaku secara kewirausahaan, dan mengikat pengusaha untuk mencapai tujuan kewirausahaan (Tasnim, Yahya \& Zainuddin, 2014). Hal ini senada dengan pendapat para peneliti lainnya bahwa passion mampu menciptakan keterlibatan yang kondusif dan berkepanjangan terhadap kegiatan se-hingga mampu memfasilitasi pencapaian tujuan dan kinerja (Mageau \& Vallerand, 2007; Vallerand, Salvy, Mageau, Elliot, Denis, Grouzet \& Blanchard, 2007).

Vallerand, Mageau, Ratelle, Leonard, Blanchard, Koestner dan Gagne (2003) menjelaskan passion merupakan kecenderungan yang kuat terhadap suatu aktivitas yang dianggap penting, disukai (bahkan mencintai) di mana mereka akan menginvestasikan waktu dan energi yang dimiliki secara maksimal. Smilor (1997) beranggapan bahwa passion merupakan keadaan emosional seperti perasaan antusiasme, kegembiraan, dan semangat.
Baum dan Locke (2004) yang telah lebih dahulu meneliti mengenai passion pada konteks kewirausahaan menyampaikan passion merupakan "rasa cinta untuk pekerjaan" dan hal ini diukur dalam "emosi cinta, keterikatan, dan kerinduan".

Emosi yang berkaitan dengan passion merujuk pada emosi positif maupun negatif memiliki efek yang mendalam pada tindakan dan hasil kewirausahaan (Baron, 2008; Shepherd, 2003).

Wincent, Cardon, Singh dan Drnovsek (2008) juga menganggap passion terdiri dari perasaan positif sangat berpengalaman untuk sesuatu yang penting bagi pengusaha. Passion dalam kegiatan kewirausahaan dialami sebagai bentuk perasaan positif yang intens terkait dengan peran yang penting untuk identitas diri sebagai pengusaha (Cardon et al., 2013).

Pengusaha tahap awal mengembangkan ikatan emosional untuk mencapai tujuan akhir dari proses menciptakan dan mempertahankan sebuah bisnis (Baron, 2008; Shepherd, 2003; Cardon et al., 2012). Hal ini memunculkan anggapan bahwa pengusaha tahap awal akan mengembangkan perasaan yang kuat terhadap usaha baru mereka dari waktu ke waktu (Wicker \& Davidson, 2015).

Sejalan dengan hal ini terdapat penelitian yang menunjukkan bahwa para pengusaha memiliki perasaan yang kuat terhadap usaha mereka seperti menggambarkan sebagai perasaan yang mirip dengan cinta (Cardon et al., 2012; Baum \& Locke, 2004). Teori segitiga cinta milik Sternberg (1986) khususnya mengenai passion digunakan sebagai kerangka yang mendukung karena membantu untuk memahami lebih dekat terkait hal ini.

Dalam sebuah penelitian, Sternberg (1997) mengasosiasikan passion dengan perasaan luar biasa seperti "Saya tidak 
bisa membayangkan hidup tanpa ....", "Saya berpikir tentang .... sepanjang hari", dan "Saya tidak bisa membayangkan orang lain membuat saya bahagia seperti ... halnya". Demikian pula perasaan positif yang kuat mirip dengan obsesi terhadap usaha yang terkadang muncul mungkin berlaku untuk pengusaha tahap awal (Cardon et al., 2013; Cardon et al., 2009).

Pada konteks pembentukan usaha baru, pengusaha tersebut dapat mengalami ketidakpastian yang sangat besar dan tingkat kompleksitas yang tinggi dalam tuntutan tugasnya (McMullen \& Sheperd, 2006). Winnen (2005) lebih lanjut menyatakan ketika pengusaha terlibat dalam suatu hal baru, passion adalah emosi yang memengaruhi pengakuan akan adanya kesempatan, misi, visi, keputusan, ketekunan, dan proses perencanaan.

Sisi lain perlu diketahui pula bahwa passion secara signifikan ikut berpengaruh terhadap pertumbuhan usaha (Baum, Locke \& Smith, 2001). Cardon et al (2012) berpendapat keberhasilan pada peluncuran produk baru dan layanan dapat dicapai karena didorong oleh adanya passion. Smilor (1997) menuturkan passion yang ada pada mereka sendiri, mampu memunculkan "bara" di dalam diri seseorang untuk membuat sesuatu yang tidak mungkin menjadi mungkin.

Passion mampu memotivasi pengusaha tahap awal untuk bekerja keras guna mencapai tujuan akhir tertentu (Bandura, 1989; Cardon, 2008; Murnieks, Mosakowski \& Cardon, 2014). Drnovsek et al (2009) dalam studinya menyatakan pengusaha harus memiliki passion untuk tetap membuat usahanya bertahan mengatasi hambatan yang sulit bahkan berkesempatan untuk memenangkan persaingan.
Passion dikaitkan dengan kreativitas yang seharusnya membantu mengatasi hambatan dalam proses (Sasser \& Koslow, 2012). Baum dan Locke (2004) percaya seseorang yang memiliki passion mampu berkinerja lebih tinggi daripada orang yang tidak memiliki passion.

Sementara itu, Cardon et al (2009) beserta Chen et al (2009) memaparkan apabila passion berkurang maka dapat menyebabkan kegagalan. Hal ini didukung oleh Vallerand et al (2003) bahwa konsep passion memainkan peran kunci kehidupan seseorang menjadi lebih berarti, sebagai jalur masuk ke keterlibatan, kinerja optimal, dan merasakan kebahagian yang intrinsik ketika berada di tengah-tengah kesulitan dan kemunduran.

Penelitian-penelitian sebelumnya (Cardon et al., 2005; Chen et al., 2009; Mitteness et al., 2012; Winnen, 2005; Baum \& Locke, 2004) mendukung bahwa passion merupakan hal penting dimiliki oleh entrepreneur dalam pendirian usaha baru sehingga usaha dapat lebih berhasil daripada pengusaha yang tidak menampilkan passion. Passion dapat mencegah pengusaha tahap awal yang keluar atau meninggalkan usahanya tersebut (Wicker \& Davidson, 2015).

Parastuty, Breitenecker, Schwarz dan Harms (2015) juga menemukan bahwa pengusaha dapat meninggalkan usahanya dengan alasan dirinya tidak memiliki passion lagi untuk menjalankan usaha. Berdasarkan penjelasan-penjelasan yang diberikan di atas sebagai upaya untuk menyingkap suatu fenomena pengusaha muda di Indonesia maka penelitian fenomenologi ini berusaha memahami dinamika passion pada pengusaha yang menjalankan usaha. Maka, diperlukan usaha atau cara untuk memahami dinamika passion agar menjadi masukan 
bagi pengusaha dalam menjaga kualitas passion demi eksistensi usaha yang telah dibangun. Fokus penelitian ini adalah passion yang dimiliki oleh pengusaha muda dan dinamika passion pada pengusaha muda ketika menjalankan usaha. Oleh sebab itu, pertanyaan penelitian dari penelitian ini adalah "Bagaimana dinamika passion pada pengusaha muda dalam menjalankan usaha?".

\section{Metode}

Penelitian ini merupakan penelitian kualitatif. Dalam rangka untuk memahami esensi dari pengalaman enterprenenur tentang dinamika passion, peneliti menggunakan pendekatan fenomenologi. Data diperoleh menggunakan metode wawancara fenomenologis semiterstruktur. Secara umum, pertanyaan yang diajukan adalah seputar pengalaman menjalankan usaha dengan passion. Kredibilitas data diperoleh melalui triangulasi metode (wawancara), analis dan triangulasi perspektif, serta dua jenis member checking, yakni member check interview dan member check of synthesized analyzed data.

\section{Karakteristik responden}

Peneliti menempatkan kriteria dalam memilih responden yakni pengusaha yang memiliki dan menjalankan sebuah usaha yang dirintis karena memiliki passion untuk berwirausaha. Responden yang termasuk disini merupakan nascent atau new business entrepreneur, sudah menjalankan usaha selama satu sampai tiga tahun. Responden berumur 18 hingga 34 tahun. Peneliti tidak membatasi jenis kelamin dari para responden penelitian ini.
Berikut dipaparkan tentang profil responden EL merupakan pendiri dari usaha SVL yang menjual barang konsumsi yaitu daily outfit dengan tema batik, natural dye, shibori dan saat ini mulai merambah ke ecoprint. SVL didirikan pada bulan Februari 2017 dan baru berjalan selama 4 bulan. EL sendiri masih berstatus sebagai seorang mahasiswa fakultas teknik jurusan arsitektur di salah satu universitas negeri di Yogyakarta. Sebelum mendirikan usaha SVL, EL pernah memiliki usaha yang bergerak di bidang jasa desain dengan mengusung tema batik namun usaha ini akhirnya ditutup karena ia merasa kewalahan dan ingin semakin mengembangkan produk sehingga memutuskan untuk mendirikan SVL. Responden ini akan disebut sebagai responden 1 (R1).

AD merupakan pendiri dari BGO yang menjual produk olahan makanan yaitu keripik jamur dan keripik pepaya. BGO didirikan pada bulan Oktober 2016 dan sudah berjalan selama 8 bulan. AD sebelumnya pernah bekerja sebagai karyawan di perusahaan manufacturing namun akhirnya memutuskan untuk keluar dari pekerjaannya dan memulai usaha BGO karena didasari oleh adanya passion. Ketika masih duduk di bangku SMA, AD pernah memiliki sebuah usaha distributor telur ayam namun akhirnya ia hentikan usaha tersebut karena merugi. Responden ini akan disebut sebagai responden 2 (R2).

LZ merupakan pendiri dari usaha TB yang didirikan pada bulan Februari 2016 dan telah berjalan selama 1,5 tahun. LZ juga bekerja sebagai seorang chef di salah satu catering di Yogyakarta. LZ adalah seorang istri dan ibu dari kedua anaknya yang masih balita. LZ sudah lama menganut gaya hidup sehat. Minat terhadap gaya hidup sehat dan memiliki 
kemampuan di dunia masak inilah yang memunculkan passion pada diri LZ untuk mulai usaha TB olahan makanan dan minuman sehat. Oleh sebab itu, LZ pun mendirikan TB dan pada bulan Desember 2016 ia pun mengusung brand baru yang masih berada di bawah naungan TB yaitu HBT dengan produk olahan minuman untuk kesehatan dan ibu menyusui.

Responden ini akan disebut sebagai responden 3 (R3).

IH merupakan pendiri usaha $\mathrm{RFH}$ yang didirikan pada November 2016 yang sudah berjalan selama 7 bulan. RFH merupakan usaha yang menjual produk jilbab dan pashmina untuk para muslimah dengan kualitas produk yang baik namun harganya terjangkau. Sewaktu dirinya berada di bangku kuliah, IH sempat menjual rok kepada teman-teman kampusnya namun tidak dilanjutkan karena ia harus menyelesaikan studi S1. IH kemudian melanjutkan studi S2 dan setelah lulus ia tetap berwirausaha. IH mendirikan usaha karena ia tidak ingin bekerja sebagai seorang karyawan tetapi memilih untuk menjadi seorang entrepreneur dan memiliki passion untuk berwirausaha. Responden ini akan disebut sebagai responden 4 (R4).

$\mathrm{RO}$ merupakan pendiri dari usaha TJJ yang bergerak di bidang jasa tour agency. TJJ berdiri pada Desember 2016 dimana usaha ini telah berjalan selama 6 bulan. RO pernah bekerja di sebuah asuransi di Yogyakarta namun ia memutuskan untuk mengundurkan diri dan mulai berwirausaha. Usaha pertama yang ia jalankan adalah OM yang menjual produk minuman. OM akhirnya vakum karena adanya keterbatasan tempat berjualan. Selanjutnya ia membuka usaha kembali yaitu TJJ yang bergerak di bidang tour agency dimana usaha ini masih sesuai dengan minatnya di travelling.
Ketidakcocokan RO dalam riwayat pekerjaan sebelumnya sebagai seorang karyawan pun membuatnya memilih pekerjaan sebagai seorang entrepreneur. Keputusan untuk menjadi entrepreneur pun didukung dengan adanya passion berwirausaha pada dirinya. Responden ini akan disebut sebagai responden 5 (R5).

\section{Pengumpulan data}

Sebelum penelitian ini dilakukan, peneliti melakukan wawancara preliminary terlebih dahulu dengan salah satu pengusaha muda yang berada di Yogyakarta untuk melihat fenomena passion yang terjadi pada diri mereka.

Terdapat dua metode yang digunakan peneliti dalam melakukan identifikasi responden yaitu melalui instansi resmi yang berkaitan dengan kewirausahaan dan melalui jaringan pribadi peneliti. Pada umumnya, instansiinstansi tersebut menerima dengan baik permohonan penelitian tesis peneliti. Pengurus instansi kemudian mempersilakan peneliti untuk secara pribadi menghubungi para pengusaha. Setelah melakukan kontak awal dengan pengusaha peneliti berkenalan, melakukan building rapport sembari menjelaskan sedikit informasi mengenai penelitian ini. Hal ini dilakukan untuk mengidentifikasi apakah pengusaha tersebut memiliki karakteristik yang sesuai dengan tema dan tujuan penelitian. Selanjutnya peneliti akan mengajukan lembar pernyataan kesediaan berpartisipasi atau informed consent kepada responden. Setelah responden menandatangani informed consent tersebut, peneliti baru memulai wawancara utama yang bertujuan melakukan pengambilan data.

Setelah memperoleh persetujuan dari responden penelitian, peneliti dapat 
memulai pengambilan data. Proses wawancara berlangsung secara informal dan menyesuaikan situasi yang memungkinkan agar tercipta rasa aman dan nyaman pada diri responden terhadap peneliti. Dokumentasi wawancara dilakukan secara auditif dengan bantuan digital recorder. Hasil rekaman wawancara kemudian ditranskip secara verbatim agar menjadi dokumentasi tertulis sesuai dengan penjelasan yang diberikan oleh responden.

\section{Analisis data}

Setelah semua data yang dikumpulkan dari peserta mencapai tahap kejenuhan, proses berikut adalah proses analisis data. Data yang sudah ditranskip kemudian dikodekan untuk menghasilkan tema yang luas. Dalam penelitian ini, peneliti akan meminjam langkah-langkah dari koding yang diusulkan oleh Strauss dan Corbin (1990).

Untuk memahami arti dari konsep yang dimiliki oleh konteksnya, peneliti akan mengikuti langkah analisis dalam pendekatan fenomenologi, yaitu yang epoche, reduksi fenomenologis, variasi imajinatif, dan syntesis (Moustakas, 1994).

\section{Hasil}

Berikut adalah temuan dari penelitian yang didasarkan oleh analisis dan interpretasi peneliti terhadap hasil wawancara yang diberikan responden. Hasil dari penelitian ini sendiri bertujuan untuk menjawab pertanyaan : "bagaimana dinamika passion pada wirausahawan muda dalam menjalankan usaha. Hasil temuan menunjukkan bahwa terbentuknya passion terdiri dari tiga aspek yaitu personal, lingkungan dan perilaku. Aspek perilaku meliputi sub aspek latar belakang individu dan emosi positif. Aspek lingkungan meliputi sub aspek ketersediaan peluang dan dukungan relasi sosial. Sedangkan, aspek perilaku meliputi aspek sikap kerja. "berminat dengan namanya healthly lifestyle" (R3,13)

"aku seseorang yang mencintai usahaku dan sebagai seorang entrepreneur aku juga enjoy ya bisa dibilang aku mencintai pekerjaanku ini" (R4, 193-199)

"ngobrol sama temen-temen komunitas usaha olahan makanan mereka bilang eh jamur krispi banyak peminatnya" (R2, 148-149) "kalo usaha sendiri tetep harus proporsional sesuai dengan porsinya dan professional " $(\mathrm{R} 2,59$ 61)

Deskripsi dinamika passion berwirausaha diawali oleh empat sub aspek yaitu ketersediaan peluang, emosi positif, latar belakang individu dan dukungan relasi sosial yang memengaruhi kemunculan passion berwirausaha.

"sekarang orang seneng makan kayak gitu nah aku melihat peluang disitu, jogja juga masih dikit banget yang jual makanya aku berani membuka usaha ini" (R3, 20-25).

"iya karna ada passion itu tadi jadi semangat, gak gampang capek, selalu penasaran tertantang juga kalo udah tau sesuatu nih kan nemu hal baru makin menggebu-gebu tu semangatnya" (R3, 168-171).

"aku adalah anak design arsitektural yang berkaitan dengan grafis kemudian dari situ aku punya basic mainin komposisi warna dan layouting" (R1, 88-92)

"saya izin orang tua mereka mengijinkan ya mana yang terbaik buat saya " (R2, 133-134) 
"aku gak akan bisa kepikiran ide untuk bikin itu semua kalo gak ada passion mbak" (R4, 191-194).

\section{Diskusi}

Berikut adalah temuan dari penelitian yang didasarkan oleh analisis dan interpretasi peneliti terhadap hasil wawancara yang diberikan responden. Hasil penelitian menunjukkan bahwa dinamika passion pada pengusaha muda memiliki peran terhadap penciptaan dan pengembangan produk, pendirian usaha dan pengembangan usaha dimana passion berperan didalamnya.

Hal itu sesuai dengan teori Cardon dan kawan-kawan (2009) yang berpendapat bahwa entrepreneur memiliki passion untuk penciptaan dan pengembangan produk sesuai dengan peran inventing yang melibatkan kegiatan "mengidentifikasi, menemukan, dan mengeksplorasi peluang baru", pendirian usaha seperti founding untuk kegiatan yang terlibat dalam "membangun usaha untuk mengkomersilkan dan memanfaatkan peluang" dan pengembangan usaha mengarah pada tahap developing yang melibatkan "memelihara, menumbuhkan, dan memperluas usaha setelah diciptakan".

Passion juga memiliki peran penting dalam keputusan untuk mendirikan usaha saat ini maupun rencana pendirian usahausaha lainnya di masa yang akan datang. Hal ini berhubungan dengan teori passion for founding yang menangani perakitan sumber keuangan, manusia, dan sosial yang diperlukan untuk menciptakan usaha baru (Cardon et al., 2009). Keinginan untuk menemukan sebuah organisasi merupakan hal penting bagi banyak pengusaha (Aldrich \& Zimmer, 1986) dan identitas peran sebagai pendiri dapat menjadi kompleks sekaligus penting bagi konsep diri seorang pengusaha (Hoang \& Gimeno, 2010).

Passion berperan pula pada pengembangan usaha yang mendorong responden untuk membuat usaha semakin berkembang besar dengan berkompetisi dalam persaingan bisnis dan agar dapat mencapai tujuan usaha. Teori yang mendukung passion dalam pengembangan usaha ini adalah passion for developing ditujukan untuk kegiatan yang berkaitan dengan pemeliharaan, pertumbuhan, dan perluasan usaha setelah diciptakan (Cardon et al., 2009). Passion disini dikaitkan dengan pertumbuhan dan perluasan usaha setelah pendirian (Cardon et al., 2009). Pengusaha termotivasi secara sadar untuk tumbuh dan mengembangkan usaha (Cliff, 1998). Pengusaha harus memiliki passion untuk tetap membuat usahanya bertahan mengatasi hambatan yang sulit bahkan berkesempatan untuk memenangkan persaingan (Drnovsek et al., 2009).

\section{Kesimpulan}

Kesimpulan yang diperoleh dari penelitian ini adalah dinamika passion ditemukan dalam serangkaian aktivitas tertentu bagi pengusaha muda. Passion teridentifikasi dalam penciptaan dan pengembangan produk yang melibatkan penemuan peluang, penciptaan, pengembangan produk atau bentuk layanan usaha untuk konsumen serta mencapai tujuan usaha itu sendiri yang dapat terealisasi melalui tahap research and development (R\&D).

Selanjutnya, pendirian usaha yaitu keputusan untuk mendirikan dan mempertahankan usaha saat ini dan pengembangan usaha yang mendorong responden untuk membuat usaha semakin berkembang besar dengan melakukan 
ekspansi bisnis untuk meningkatkan hasil penjualan serta dapat mencapai tujuan usaha. Ketiga hal tersebut diketahui sesuai dengan teori yang diajukan oleh Cardon et al (2009) mengenai passion dalam berwirausaha yang merujuk pada tiga domain seperti passion for inventing, founding dan developing.

Jika dilihat kondisinya di Indonesia melalui penelitian ini, peneliti menemukan adanya dukungan, saran atau berdiskusi dengan relasi sosial atau orang terdekat yaitu orang tua, suami dan komunitas pengusaha yang ikut mendukung passion responden dalam menjalankan usahanya. Begitu pula halnya dengan peran dari latar belakang yang bersifat individual dari responden seperti minat, latar belakang pendidikan, pengetahuan yang dimiliki, skill, dan pengalaman riwayat kerja muncul untuk membentuk passion berwirausaha tersebut menjadi semakin optimal.

\section{Saran}

Hasil penelitian ini dapat dimanfaatkan oleh pengusaha muda yang berminat untuk membangun usaha atau telah menjalankan usaha. Dengan merujuk kepada hasil penelitian, maka individu yang berminat membangun usaha dapat mempersiapkan mengenai passion yang dimiliki untuk dilibatkan dalam aktivitas pendirian usaha. Selanjutnya, bagi yang sudah memiliki usaha dan sedang menjalankannya dapat mempergunakan passion untuk aktivitas "menemukan" peluang, pengembangan produk dan layanan yang baru dalam usaha.

Sama halnya dengan ketika ingin mengembangkan usaha, passion mampu ikut berpengaruh dalam proses pengembangan usaha untuk pemeliharaan, pertumbuhan, dan perluasan usaha setelah diciptakan. Begitu pula dengan pengusaha muda yang sedang mengalami permasalahan dalam usaha mereka bahwa hasil penelitian dapat menjadi bahan acuan untuk melakukan refleksi dan evaluasi terhadap cara mereka dalam mengelola passion untuk kepentingan jalannya usaha mereka, sehingga dapat mengambil langkah perbaikan atau pencegahan yang diperlukan. Hal ini ikut berperan apabila jumlah pengusaha muda khususnya yang mengandalkan passion mereka dalam berwirausaha semakin banyak maka dapat membantu menambah ketersediaan lapangan kerja.

\section{Kepustakaan}

Aldrich, H. W., Zimmer, C. (1986). Entrepreneurship through social networks. In: Sexton, D., Smilor, R. (Eds.), The art and science of entrepreneurship. Ballinger: Cambridge.

Bandura, A. (1989). Human agency in social cognitive theory. American Psychologist, 44(9), 1175.

Baron, R. (2008). The role of affect in the entrepreneurial process. Academy of Management Review, 33, 328-340.

Baum, J. R., Locke, E. A., \& Smith, K. G. (2001). A multidimensional model of venture growth. Academy of Management Journal, 44(2), 292-304.

Baum, J. R., \& Locke, E. A. (2004). The relationship of entrepreneurial traits, skill, and motivation to subsequent venture growth. Journal of Applied Psychology, 89(4), 587-598.

Brännback, M., Carsrud, A., Elfving, J., \& Krueger, N. K. (2006). Sex, drugs, and entrepreneurial passion? An exploratory study. Paper presented at the Babson College Entrepreneurship Research Conference.

Cardon, M. S., Zietsma, C., Saparito, P., 
Matherne, B., \& Davis, C. (2005). A tale of passion: New insights into entrepreneurship from a parenthood metaphor. Journal of Business Venturing, 20(1), 23-45.

Cardon, M. S. (2008). Is passion contagious? The transference of entrepreneurial emotion to employees. Human Resource Management Review, 18(2), 77-86.

Cardon, M. S., Foo, M. D., Shepherd, D. A., \& Wiklund, J. (2012). Exploring the heart: Entrepreneurial emotion is a hot topic. Entrepreneurship Theory and Practice, 36, 1-10.

Cardon, M. S., Sudek, R., \& Mitteness, C. (2009). The impact of perceived entrepreneurial passion on angel investing. Frontiers of Entrepreneurship Research, 29(2), 1.

Cardon, M. S., Gregoire, D., \& Stevens, C. E. (2009). The discriminant validity of entrepreneurial passion. Academy of Management Meetings, Chicago, IL.

Cardon, M. S., Gregoire, D. A., Stevens, C. E., \& Patel, P. C. (2013). Measuring entrepreneurial passion: Conceptual foundations and scale validation. Journal of Business Venturing, 28(3), 373-396.

Cardon, M. S., Wincent, J., Singh. J., \& Drnovsek, M. (2009). The nature and experience of entrepreneurial passion. Academy of Management Review, 34(3), 511-32.

Chen, X., Yao, X., \& Kotha, S. (2009). Entrepreneur passion and preparedness in business plan presentations: A persuasion analysis of venture capitalists' funding decisions. Academy of Management Journal, 52(1), 199-214.

Cliff, J. E. (1998). Does one size fit all? Exploring the relationship between attitudes towards growth, gender, and business size. Journal of Business Venturing 13, 523-542.

Collewaert, V., Anseel, F., Crommelinck, M., De Beuckelaer, A., Vermeire, J. (2016). When passion fades: Disentangling the temporal dynamics of entrepreneurial passion for founding. Journal of Management Studies, 53(6), 996-995. doi: 10.1111/joms.12193

Darwanto (2012). Peran entrepreneurship dalam mendorong pertumbuhan ekonomi dan peningkatan kesejahteraan masyarakat. Diseminasi riset terapan bidang manajemen \& bisnis tingkat nasional jurusan administrasi bisnis Politeknik Negeri Semarang

Deniz, N., Boz, I. T., \& Ertosun, O. G., (2011). The relationship between entrepreneur's level of perceived business-related fear and business performance. Procedia Social and Behavioral Sciences, 24, 579-600.

Drnovsek, M., Cardon, M. S., \& Murnieks, C. Y. (2009). Collective passion in entrepreneurial teams. A. Carsrud, \& M. Brannback (Eds.), The entrepreneurial mind (pp. 191-215). New York: Springer.

GEM. (2013). GEM 2013 Global Report. https://www.gemconsortium.org/rep ort. Diakses pada 1 Januari 2017 pukul 12.00 .

Hoang, Ha \& Gimeno, Javier. (2010). Becoming an entrepreneur: A theory of entrepreneurial identity. Journal of Business Venturing, 2010, vol. 25, issue 1, 41-53.

DOI: 10.1016/j.jbusvent.2008.07.002

Katz, J. A., \& Green, R. P. (2007). Entrepreneurial small business. New York: McGraw-Hill.

Kew, J., Herrington, M., Litovsky, Y., \& Gale, H. (2013). Generation entrepreneur? The state of global 
youthship. Youth Business International and Global Entrepreneurship Monitor, Newcastle.

Liliyah, Arie. (2015). Jumlah Wirausaha Indonesia Hanya $0,43 \%$ dari Total Populasi.

https://swa.co.id/swa/trends/managem ent/jumlah-wirausaha-indonesia-

hanya-043-dari-total-populasi. Diakses pada 1 Januari 2017 pukul 12.00.

Mageau, G. A., \& Vallerand, R. J. (2007). The moderating effect of passion on the relation between activity engagement and positive affect. Motivation and Emotion, 31(4), 312-321.

McMullen, J. S., \& Shepherd, D. A. (2006). Entrepreneurial action and the role of uncertainty in the theory of the entrepreneur. Academy of Management Review, 31(1), 132-52.

Mitteness, C., Sudek, R., \& Cardon, M. S. (2012). Investor characteristics that determine whether perceived passion leads to higher evaluations of funding potential. Journal of Business Venturing, 27, 592-606.

Moustakas, C. (1994). Phenomenological research methods. Thousand Oaks: Sage Publication, Inc.

Murnieks, C. Y., Mosakowski, E., \& Cardon, M. S. (2014). Pathways of passion identity centrality, passion, and behavior among entrepreneurs. Journal of Management, 40(6), 1583-1606.

Parastuty, Z., Breitenecker, R. J., Schwarz, E. J., \& Harms, R. (2016). Exploring the reasons and ways to exit: The entrepreneur perspective. Diedit oleh D. Bogenhold, J. Bonnet, M. Dejardin, \& D. G. P. de Lema, Contemporary Entrepreneurship: Multidisciplinary Perspectives on Innovation and Growth (159-172). New York: Springer.
Sasser, S. L., \& Koslow, S. (2012). Passion, expertise, politics, and support. Journal of Advertising, 41(3), 5-18.

Sternberg, R. J. (1986). A triangular theory of love. Psychological Review, 93(2), 119.

Sternberg, R. J. (1997). Construct validation of a triangular love scale. European Journal of Social Psychology, 313-335

Shepherd, D. A. (2003). Learning from business failure: Propositions of grief recovery for the selfemployed. Academy of Management Review, 28(2), 318-328.

Smilor, R. W. (1997). Entrepreneurship: Reflections on a subversive activity. Journal of Business Venturing, 12(5), 341-346.

Strauss, A., \& Corbin, J. (1990). Basics of qualitative research: Grounded theory procedures and techniques. Newbury Park : Sage Publications, Inc.

Tasnim, R., Yahya, S., \& Zainuddin, M.N. (2014). “Im loving it!" What makes the successful entrepreneur affectively committed to entrepreneurial performance? The Journal of Applied Management and Entrepreneurship, 19(2), 27-52.

Vallerand, R. J., Mageau, G. A., Ratelle, C., Leonard, M., Blanchard, C., \& Koestner, R., (2003). Les Passions de l' Ame: On obsessive and harmonious passion. Journal of Personality and Social Psychology, 85(4), 756-767.

Van Praag, C. M., \& Versloot, P. H. (2007). What is the value of entrepreneurship? A review of recent research. Small Bussiness Economy, 29(4), 351-82.

Vallerand, R. J., Salvy, S. J., Mageau, G. A., Elliot, A. J., Denis, P. L., Grouzet, F. 
M., \& Blanchard, C. (2007). On the role of passion in performance. Journal of Personality, 75(3), 505-534.

Wincent, J., Cardon, M. S., Singh, J., \& Drnovsek, M. (2008). Entrepreneurial affect: The distinction between emotion and passion. In Academy of Management Conference. Anaheim, CA. Winnen, C. J. (2005). To be or not to be: The role of passion and obsession in the entrepreneurial process. (Unpublished doctoral dissertation). University of St. Thomas, St. Paul.

Wicker, C., \& Davidsson, P. (2015). The entrepreneurial break-up: Disengaging from the start-up phase. Research Handbook of Entrepreneurial Exit, 197. 